\title{
SYMBOLIKA PAWILONÓW NARODOWYCH PODCZAS WYSTAW ŚWIATOWYCH ${ }^{2}$
}

\begin{abstract}
Wystawy światowe mają ponad półtorawieczną historię. Z czasem ich funkcje zmieniały się - pierwotnie podczas ich trwania pokazywano osiągnięcia techniczne i wynalazki, a następnie promowano dorobek kulturowy. Obecne Expo służą przede wszystkim kreowaniu wizerunku uczestniczących w nich państw. Kluczowe znaczenie w tym względzie ma symbolika pawilonów narodowych, gdyż to oryginalny wygląd tych budowli zachęca uczestników wystawy do odwiedzenia danej ekspozycji, na długo pozostaje w pamięci oraz pojawia się w wielu przekazach medialnych. Celem niniejszego opracowania jest systematyzacja indywidualnych pawilonów narodowych zbudowanych w ramach dwóch ostatnich wystaw światowych - Expo 2010 w Szanghaju oraz Expo 2015 w Mediolanie. Na podstawie obserwacji przeprowadzonej przez autora zaproponowano systematykę pawilonów w kontekście ich wymiaru symbolicznego, przywołując liczne przykłady. Podstawowa konstatacja, która wyłania się z przeprowadzonej obserwacji wskazuje na to, że symboliczny charakter obiektów wystawowych sprowadza się do odnoszenia się do następujących atrybutów krajów uczestniczących w Expo: kultury, historii, religii, gospodarki, przyrody, architektury. Symbolika budowli z ekspozycjami narodowymi może także nawiązywać wprost do idei przewodniej wystawy, jak również do innych (abstrakcyjnych) elementów. Ujęcie symbolicznego wymiaru pawilonów w zaproponowane kategorie może okazać się przydatne przy budowaniu narzędzia pomiarowego do wykorzystania w badaniach realizowanych podczas przyszłych edycji Expo, a dotyczących postrzegania ekspozycji narodowych.
\end{abstract}

Słowa kluczowe: wystawy światowe, Expo, symbolika budowli, pawilony narodowe.

\section{WPROWADZENIE}

Historia wystaw światowych obejmuje ponad półtora wieku. Od samego początku główną ideą tych wydarzeń było prezentowanie bieżących osiągnięć cywilizacyjnych - zarówno w kontekście globalnym, jak również w wymiarze poszczególnych państw. Pierwotnie niewielkie ekspozycje narodowe znajdowały się w jednym miejscu, wewnątrz dużych pawilonów (np. taka sytuacja miała miejsce podczas pierwszej wystawy światowej, która

${ }^{1}$ Dr hab. Marcin Gębarowski, Katedra Zarządzania Procesowego, Wydział Towaroznawstwa i Zarządzania Produktem, Uniwersytet Ekonomiczny w Krakowie; ul. Rakowicka 27, 31-510 Kraków; e-mail: marcin.gebarowski@uek.krakow.pl.

Marcin Gębarowski, DSc, PhD, Department of Process Management, Faculty of Commodity Science and Product Management, Cracow University of Economics; ul. Rakowicka 27, 31-510 Cracow; e-mail: marcin.gebarowski@uek.krakow.pl.

2 Publikacja sfinansowana ze środków przyznanych Wydziałowi Towaroznawstwa i Zarządzania Produktem Uniwersytetu Ekonomicznego w Krakowie w ramach dotacji na utrzymanie potencjału badawczego. 
w 1851 r. odbyła się w Londynie, w nieistniejącym już Kryształowym Pałacu). Z czasem prezentacje poszczególnych krajów stawały się coraz większe, jak również zaczęto zdawać sobie sprawę z możliwości wyróżnienia poszczególnych ekspozycji przez oddzielanie ich od pozostałych stanowisk ekspozycyjnych i pokazywanie w oddzielnych obiektach. W konsekwencji podczas wystaw światowych pojawiły się pawilony narodowe, często o oryginalnej bryle, stanowiące podczas obecnych Expo większość budowli składających się na tereny wystawowe.

Wygląd pawilonów przygotowywanych na Expo omawiany był już w literaturze naukowej - zarówno zagranicznej ${ }^{3}$, jak i krajowej ${ }^{4}$. Jednak zagadnienie to wydaje się być warte dalszego eksplorowania i opisywania z kilku względów. Oprócz wymiaru stricte marketingowego (wizerunkowego), wygląd oraz wielkość pawilonów stanowią często reprezentację potencjału kraju-gospodarza (w aspektach: kulturalnym, przyrodniczym, naukowym, technicznym), jak również emanację jego dążeń. Ponadto pawilon zawsze powinien odzwierciedlać główną ideę danej edycji wystawy światowej. Z tych względów wybór projektu budowli, w której będzie prezentował się uczestnik Expo, nie jest prostym zadaniem. Dodatkowo, na wagę takiej decyzji wpływa nakład pracy wielu osób, które muszą zaangażować się w przygotowanie budowli często w odległym zakątku globu, jak również konieczność przeznaczenia znacznych środków finansowych na wybudowanie oraz obsługę pawilonu ${ }^{5}$. Ta wieloaspektowość przywołanego zagadnienia sprawia, że istnieją obszary dotąd nieopisane w publikacjach naukowych. Jednym z nich jest wymiar marketingowy, determinowany symboliką zaproponowaną przez twórców obiektów wystawowych.

Celem niniejszego opracowania jest systematyzacja podejść do konstruowania pawilonów narodowych na podstawie dwóch ostatnich uniwersalnych wystaw światowych - Expo 2010, które odbyło się w Szanghaju, oraz Expo 2015, które miało miejsce w Mediolanie. W oparciu o obserwację przeprowadzoną przez autora tekstu zaproponowano systematykę pawilonów w kontekście ich wymiaru symbolicznego. Stworzona systematyka może stanowić podstawę do przeprowadzenia badań dotyczących postrzegania pawilonów narodowych przez uczestników przyszłych wystaw światowych.

\footnotetext{
${ }^{3}$ Por. m.in. P. Harvey, Nations on display: Technology and culture in Expo '92, „Science as Culture”, 5 (1992), s. 85-105; Z. Zhou, Y. Chen, Scale study of sites and pavilions for World Expo 2010, „Frontiers of Architecture and Civil Engineering in China”, 2(1) (2008), s. 102-106; Y. Deng, Conceptualizing mega-event flagships - A case study of China Pavilion of Expo 2010 Shanghai China, „Frontiers of Architectural Research”, 2 (2013), s. 107-115; J. Wang, The Shanghai Expo as a Site for Nation Branding [w:] Shaping China's Global Imagination: Branding Nations at the World Expo, Palgrave Macmillan, New York 2013, s. 43-62.

${ }^{4}$ Por. m.in.: W. Świątek, Trzy polskie pawilony na Wystawy Światowe Expo - trzy stopnie jakości, „Czasopismo Techniczne. Mechanika”, 26 (2012), s. 331-348; I. Sykta, Ewolucja idei postepu i wizji miast przyszłości zapisana $w$ krajobrazach, obiektach i pokazach wystaw światowych - od Londynu 1851 do Nowego Jorku 1939, „Przestrzeń i Forma”, 21 (2014), s. 353-376; I. Sykta, Ewolucja idei postępu i wizji miast przyszłości zapisana w krajobrazach, obiektach i pokazach wystaw światowych - od Brukseli 1958 do Osaki 1970, „Przestrzeń i Forma”, 22 (2014), s. 105-124; I. Sykta, Synergia terenów wystaw światowych i struktur przestrzennych miast-gospodarzy, „Budownictwo i Architektura", 16(2) (2017), s. 5-30.

${ }^{5}$ Wysokie koszty uczestnictwa w Expo decydowały już niejednokrotnie o absencji podczas wystaw światowych - i to zamożnych państw, np. w 2015 r. taka sytuacja miała miejsce w przypadku Kanady oraz Australii (por. U. Bacchi, Expo Milano 2015: Canada and Australia say no to world fair over budget, http://www.ibtimes.co.uk/expo-milano-2015-canada-australia-say-no-world-fairover-budget-1499177).
} 


\section{ROZWÓJ WYSTAW ŚWIATOWYCH}

Za wydarzenie, które rozpoczęło historię wystaw światowych, uznaje się Wielką Wystawę Przemysłu Wszystkich Narodów (The Great Exhibition). Odbyła się ona w 1851 r. w londyńskim Hyde Parku. Przez kolejne półtora wieku wystawy stały się ważnym miejscem spotkań przedstawicieli państw z całego świata - pierwotnie przyczyniając się do kreowania wymiany handlowej i kulturalnej, a następnie promując poszczególne nacje oraz ich osiągnięcia w różnych obszarach.

W przeszłości wystawy światowe organizowano nieregularnie - co kilka, a nawet co kilkanaście lat. W obecnym stuleciu Expo odbywają się co pięć lat i trwają przez pół roku (tabela 1). Oprócz wystaw uniwersalnych organizowane są również tzw. „,małe Expo”, czyli wystawy specjalistyczne. Są one mniejsze, bardziej jednorodne tematycznie i trwają 3 miesiące. Ostatnie wydarzenie specjalistyczne odbyło się w Astanie w 2017 r.

Tabela 1. Charakterystyka uniwersalnych wystaw światowych w XXI w.

\begin{tabular}{|l|c|c|c|c|}
\hline \multicolumn{1}{|c|}{ Wystawa } & Miasto & Powierzchnia & Liczba krajów & $\begin{array}{c}\text { Frekwencja } \\
\text { zwiedzających }\end{array}$ \\
\hline Expo 2000 & Hanower & $160 \mathrm{ha}$ & 155 & $18,1 \mathrm{mln}$ \\
\hline Expo 2005 & Aichi & $173 \mathrm{ha}$ & 120 & $22,0 \mathrm{mln}$ \\
\hline Expo 2010 & Szanghaj & $528 \mathrm{ha}$ & 190 & $73,0 \mathrm{mln}$ \\
\hline Expo 2015 & Madiolan & $110 \mathrm{ha}$ & 145 & $22,0 \mathrm{mln}$ \\
\hline
\end{tabular}

Źródło: opracowanie własne na podstawie: http://www.bie-paris.org, http://www.expomuseum.com.

Wystawy światowe, wraz z rozwojem ludzkości, zmieniały pełnione przez siebie funkcje. W tym kontekście w procesie ewolucji tego typu wydarzeń wskazuje się na wystąpienie trzech okresów ${ }^{6}$ :

- ery industrializacji (1851-1938) - koncentrowano się przede wszystkim na premierowym pokazywaniu osiągnięć przemysłowych oraz wynalazków kluczowych dla rozwoju cywilizacji (takimi wynalazkami były m.in. telefon, maszyna do pisania, winda hydrauliczna);

- ery wymiany kulturalnej (1939-1987) - główny akcent kładziono na eksponowanie walorów kulturowych poszczególnych państw, komunikację międzykulturową oraz otwieranie się społeczeństw na ludzi z zewnątrz i nowe wartości;

- ery kreowania wizerunku narodowego (od 1988 r. - do czasów współczesnych) w ekspozycjach zaczęły dominować wyróżniki poszczególnych wystawców, znajdywane w różnych obszarach (np. przyrodzie, sporcie, kulturze, nauce).

Do tej pory zorganizowano blisko 70 wystaw światowych o różnym znaczeniu oraz charakterze, przy czym 34 z nich miały status największych wydarzeń - uniwersalnych. Kolejna taka wystawa odbędzie się w 2020 r. w Dubaju, zaś specjalistyczne Expo w 2023 r. w Buenos Aires. Prawa do organizowania wystaw przyznaje Międzynarodowe Biuro Wystaw - BIE (Bureau International des Expositions). Organizacja powstała w 1928 r. w Paryżu, a jej członkiem-założycielem była Polska. Obecnie BIE zrzesza 170 państw.

${ }^{6}$ M. Hughes, Making an impact: The power of World Expo, „Vision - Fresh Perspectives from Dubai”, March (2012), s. 70-71. 
Historia udziału Polski w wystawach światowych nie jest długa. Wpłynęły na to względy regulaminowe oraz polityczne. Od samego początku organizowania tego typu wydarzeń BIE przyjęła zasadę, że dopuszcza do eksponowania jedynie reprezentacje państwowe. W początkowej fazie rozwoju wystaw Polska nie miała swojej państwowości. Z kolei w okresie kilku dekad po II wojnie światowej nasz kraj nie prezentował się ze względu na miejsca urządzania Expo, którymi były miasta znajdujące się po drugiej stronie „,̇elaznej kurtyny”. W związku z tym polskich pawilonów narodowych nie powstało wiele. Nasz kraj pierwszą okazję do zaprezentowania się miał 1933 r. w Chicago i był to skromny początek uczestnictwa w wystawach światowych. Pierwszy obiekt z przeznaczeniem do samodzielnego prezentowania się Polska wybudowano cztery lata później, na wystawę paryską $^{7} \mathrm{Z}$ własnym pawilonem nasz kraj powrócił dopiero na Expo 2000 w Hanowerze. W późniejszych latach Polska miała charakterystyczne, silnie wyróżniające się oryginalnością, pawilony podczas wystawy specjalistycznej w Aichi, która odbyła się w 2005 r., jak również podczas wystaw uniwersalnych w 2010 r. (Szanghaj) oraz 2015 r. (Mediolan).

\section{STRUKTURA TERENÓW WYSTAW ŚWIATOWYCH}

Obiekty ekspozycyjne, budowane na terenach wystaw światowych, można podzielić na pięć grup. Są to pawilony:

- narodowe - indywidualne,

- narodowe - kolektywne,

- instytucji międzynarodowych,

- tematyczne,

- komercyjne (partnerów i sponsorów wystawy).

Najliczniejszą grupę budowli podczas wystaw światowych stanowią indywidualne pawilony narodowe, będące przedmiotem zainteresowania w niniejszym opracowaniu. Są to obiekty o zróżnicowanej wielkości, budowane na działkach przydzielonych przez kraj-gospodarza. Na wygląd takich pawilonów mają wpływ wyłącznie stawiające je państwa, które jednak muszą stosować się do pewnych zaleceń organizatorów wystawy ${ }^{8}$.

Ekspozycje krajów uczestniczących w Expo, oprócz pawilonów indywidualnych, znajdują się również w pawilonach kolektywnych, stawianych przez gospodarza wystawy światowej. W jednym takim obiekcie prezentuje się kilka lub kilkanaście krajów, najczęściej z konkretnego regionu świata ${ }^{9}$. Kraje mogą być również łączone w ujęciu tematycz-

\footnotetext{
${ }^{7}$ Architektura pawilonu narodowego wyróżniona została jako jeden z trzech najdoskonalszych obiektów wystawy (por. W. Świątek, Trzy polskie pawilony na Wystawy Światowe Expo - trzy stopnie jakości, „Czasopismo Techniczne. Mechanika”, 26 (2012), s. 332).

${ }^{8} \mathrm{Na}$ przykład zgodnie z zaleceniami organizatorów Expo 2010 wysokość wszystkich pawilonów podczas tej wystawy nie mogła przekraczać $20 \mathrm{~m}$. Wyjątkiem była budowla, a której prezentował się kraj-gospodarz. Chiński pawilon, w kształcie ściętego odwróconego stożka, miał się silnie wyróżniać na tle pozostałych ekspozycji narodowych. Jego wysokość liczyła 63 m, czyli był on trzykrotnie wyższy od budowli reprezentujących inne państwa.

9 Podczas Expo 2010 tylko 8 krajów afrykańskich (Algieria, Angola, Egipt, Libia, Maroko, Nigeria, Republika Południowej Afryki, Tunezja) wystawiały się w pawilonach indywidualnych. Pozostałe 42 państwa $\mathrm{z}$ tego kontynentu prezentowały swoje ekspozycje w kolektywnym obiekcie (Africa Pavilion).
} 
nym ${ }^{10}$. Na kolektywną formę prezentacji decydują się z reguły mniejsze państwa oraz te kraje, które nie są w stanie przeznaczyć dużych środków finansowych na wybudowanie obiektów dla własnych, oddzielnych ekspozycji. W przypadku pawilonów kolektywnych konstrukcja pozbawiona jest oryginalnego charakteru, gdyż projekt narzuca organizator wystawy.

Podczas wystaw światowych oddzielne pawilony budowane są również dla dużych organizacji międzynarodowych, które za sprawą obecności na Expo starają się promować swoją działalność oraz pozyskiwać na nią środki finansowe ${ }^{11}$. Podczas ostatnich wystaw swój pawilon posiadała BIE, w którym - pod hasłem „World Exposition Museum” - prezentowano historię wystaw światowych, w tym m.in. miejsca, w których odbywały się poszczególne wydarzenia; przedstawiane na nich odkrycia, ważne dla ludzkości; obiekty architektoniczne, które pozostały w przestrzeni miejskiej po Expo (np. Wieża Eiffla).

Pawilony tematyczne przygotowywane są przez organizatorów wystawy - BIE oraz kraj-gospodarza. Niekiedy wygląd zewnętrzny takich budowli, a zawsze znajdujące się w ich wnętrzach ekspozycje, silnie nawiązują do idei przewodniej Expo. Przy czym to nawiązanie może mieć miejsce przez pryzmat całej cywilizacji ${ }^{12}$, jak również kraju gospoda$\mathrm{rza}^{13}$. Ekspozycje pawilonów tematycznych mają przede wszystkim edukować, uwrażliwiając uczestników wystaw na wybrane, ważne społecznie kwestie.

W pawilonach komercyjnych umieszczane są prezentacje marek, które zostały oficjalnymi partnerami lub sponsorami Expo ${ }^{14}$. Ekspozycje te, mimo komercyjnego charakteru, nawiązują do idei przewodniej wystawy.

Oprócz pawilonów wystawowych tereny Expo uzupełniają dodatkowe elementy infrastruktury. Najważniejsze z nich to: centrum prasowe, sale kongresowe, sklepy, restauracje, miejsca do specjalnych pokazów, teatr na otwartym powietrzu, sfery rekreacyjne, place zabaw dla dzieci, ciągi komunikacyjne.

${ }^{10}$ Podczas Expo 2015 utworzono 9 zbiorczych pawilonów (nazwanych klastrami) dla ogółem 77 krajów, które prezentowały się w nich m.in. pod następującymi hasłami: „Ryż”, „Kawa”, „Kakao i czekolada”, „Przyprawy”.

11 Egzemplifikacją organizacji, które ze swoimi pawilonami były obecne w Szanghaju lub Mediolanie są: Czerwony Krzyż i Czerwony Półksiężyc, Organizacja Narodów Zjednoczonych, Save the Children.

12 Przykładem jest tzw. Pawilon Zero z 2015 r., w którym zaprezentowano rozwój ludzkości przez pryzmat zdobywania pożywienia - od udomowienia zwierząt, początków upraw i wynalezienia narzędzi, aż do czasów współczesnych, gdy wartość żywności wyznacza giełda. W ramach tej ekspozycji zwrócono także uwagę na problem wyrzucania jedzenia, jak również produkowania śmieci i zanieczyszczania środowiska naturalnego.

${ }^{13}$ Podczas Expo 2015 ekspozycję w jednym pawilonie tematycznych zatytułowano „Park różnorodności biologicznej” (Biodiversity Park). Ekspozycja służyła przede wszystkim zwróceniu uwagi na wyjątkowe osiągnięcia kraju-gospodarza (Włoch) w obszarze ochrony środowiska, jak również rozwoju rolnictwa i produkcji żywności.

14 Podczas dwóch ostatnich wydarzeń w takich obiektach prezentowały się m.in. następujące marki: CISCO, Coca-Cola, Ferrero, New Holland Agriculture, Wanke. 


\section{PRZEGLĄD PAWILONÓW WYSTAWOWYCH W KONTEKŚCIE ICH SYMBOLICZNEGO WYMIARU}

Stownik wspótczesnego języka polskiego przez termin „symbolika” rozumie „symboliczny charakter czegoś; symbolizm" ${ }^{15}$. Podobnie Stownik wyrazów obcych i zwrotów obcojęzycznych pojęcie to utożsamia ze „znaczeniem symbolicznym" "16. Bazując zatem na słownikowych ujęciach przez symbolikę pawilonów wystawowych należy rozumieć alegoryczny wymiar takich budowli, odnoszący się do skojarzeń, jakie u większości uczestników Expo wywołuje wygląd obiektów - kształt; kompozycja kolorystyczna; materiał, z którego wykonano elewację; aranżacja najbliższego otoczenia.

W oparciu o obserwację przeprowadzoną podczas dwóch ostatnich wystaw światowych (Expo 2010 i Expo 2015) - przy uwzględnieniu skojarzeń, jakie wszystkie pawilony narodowe miały wywoływać u uczestników Expo - budowle te można ująć w ramach systematyki obejmującej osiem grup. Symbolika obiektów wystawowych przejawiała się bowiem przez odnoszenie się do państw-gospodarzy pawilonów za sprawą bazowania na ich:

- kulturze,

- historii,

- religii,

- gospodarce,

- przyrodzie,

- architekturze,

- wyróżniku nawiązującym wprost do idei przewodniej wystawy,

- innym, abstrakcyjnym wyróżniku.

Oddzielną grupę stanowiły obiekty wystawowe o neutralnej bryle - pozbawione znaczenia symbolicznego. W grupie indywidualnych pawilonów narodowych pojawiały się one jednak rzadko.

Egzemplifikacji dla poszczególnych grup można dokonać przywołując wybrane obiekty wystawowe wybudowane na czas wystaw światowych, które odbyły się w Szanghaju oraz Mediolanie (tabela 2).

Tabela 2. Przykłady pawilonów narodowych z różnych grup odwołań symbolicznych

\begin{tabular}{|c|c|c|c|}
\hline $\begin{array}{c}\text { Obszar } \\
\text { odwołania }\end{array}$ & Kraj & Opis pawilonu & Zdjęcie \\
\hline kultura & Angola $^{2}$ & $\begin{array}{l}\text { Na elewacji pawilonu umieszczono } \\
\text { drewniane elementy, będące odwzoro- } \\
\text { waniem kształtów geometrycznych, } \\
\text { typowych dla tkanin z tego kraju }\end{array}$ & \\
\hline
\end{tabular}

15 B. Dunaj (red.), Stownik wspótczesnego języka polskiego, Warszawa 1996, s. 1079.

${ }^{16}$ W. Kopaliński, Stownik wyrazów obcych i zwrotów obcojęzycznych z almanachem, Warszawa 2007, s. 551. 
Tabela 2 (cd.). Przykłady pawilonów narodowych z różnych grup odwołań symbolicznych

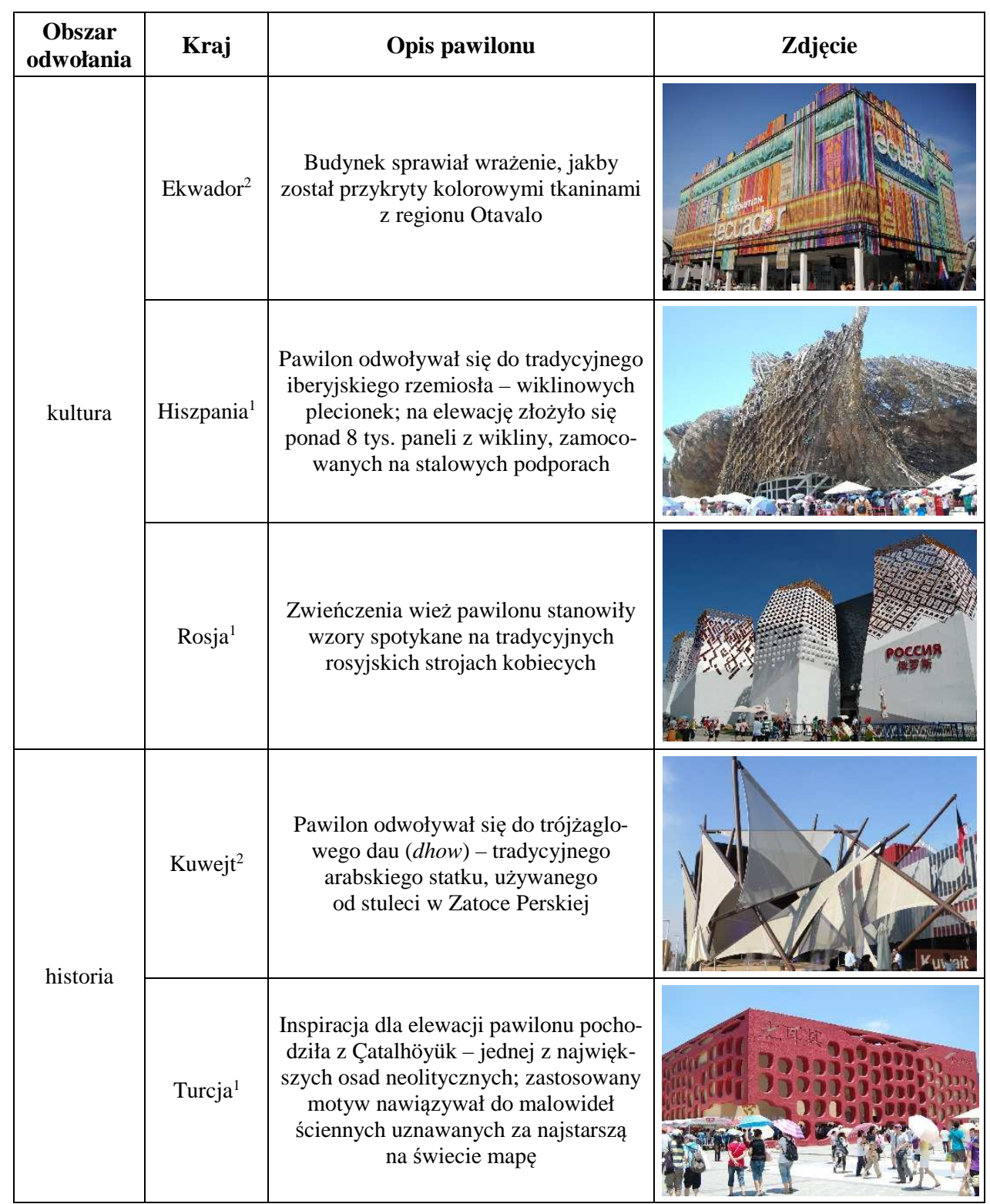


Tabela 2 (cd.). Przykłady pawilonów narodowych z różnych grup odwołań symbolicznych

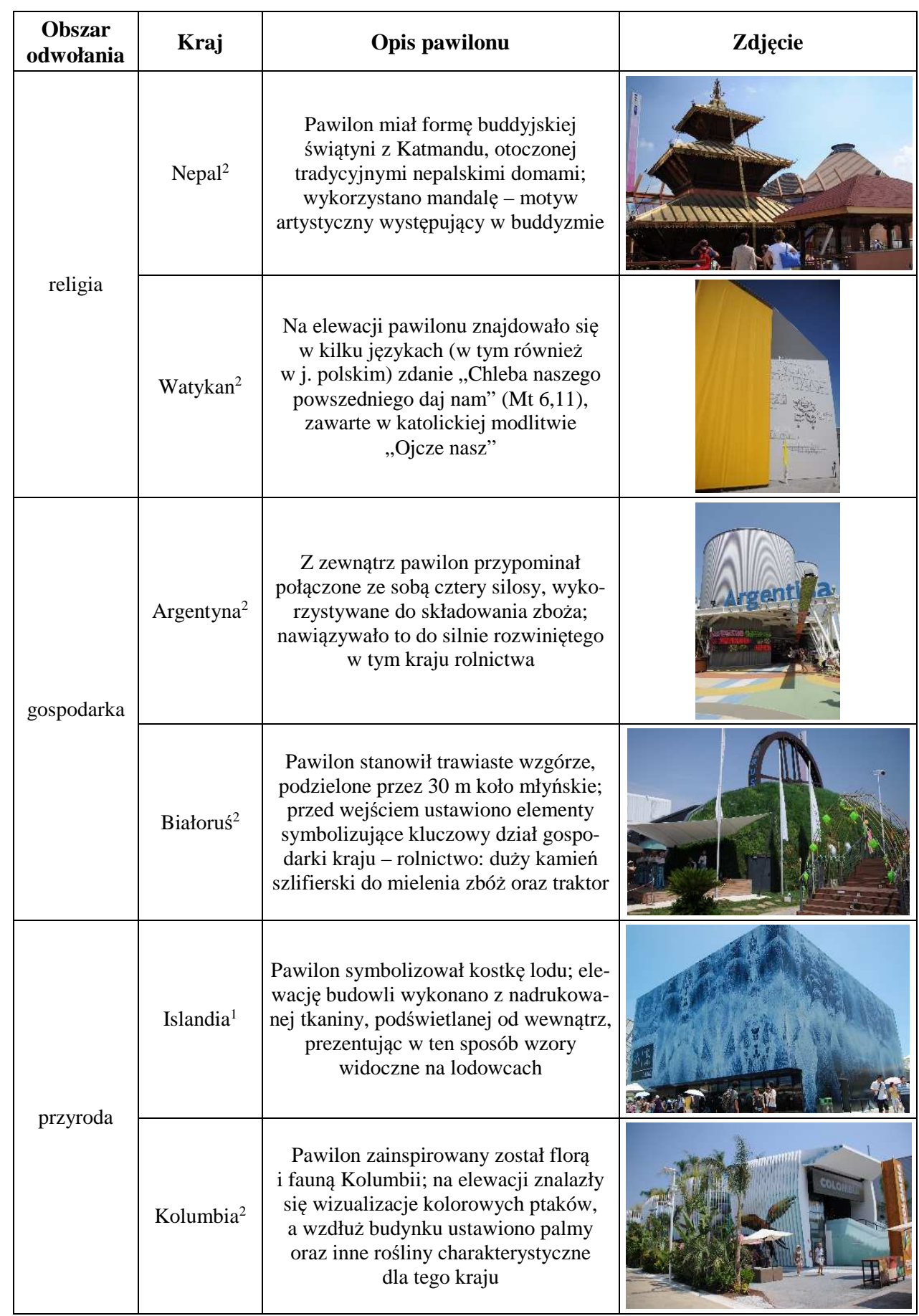


Tabela 2 (cd.). Przykłady pawilonów narodowych z różnych grup odwołań symbolicznych

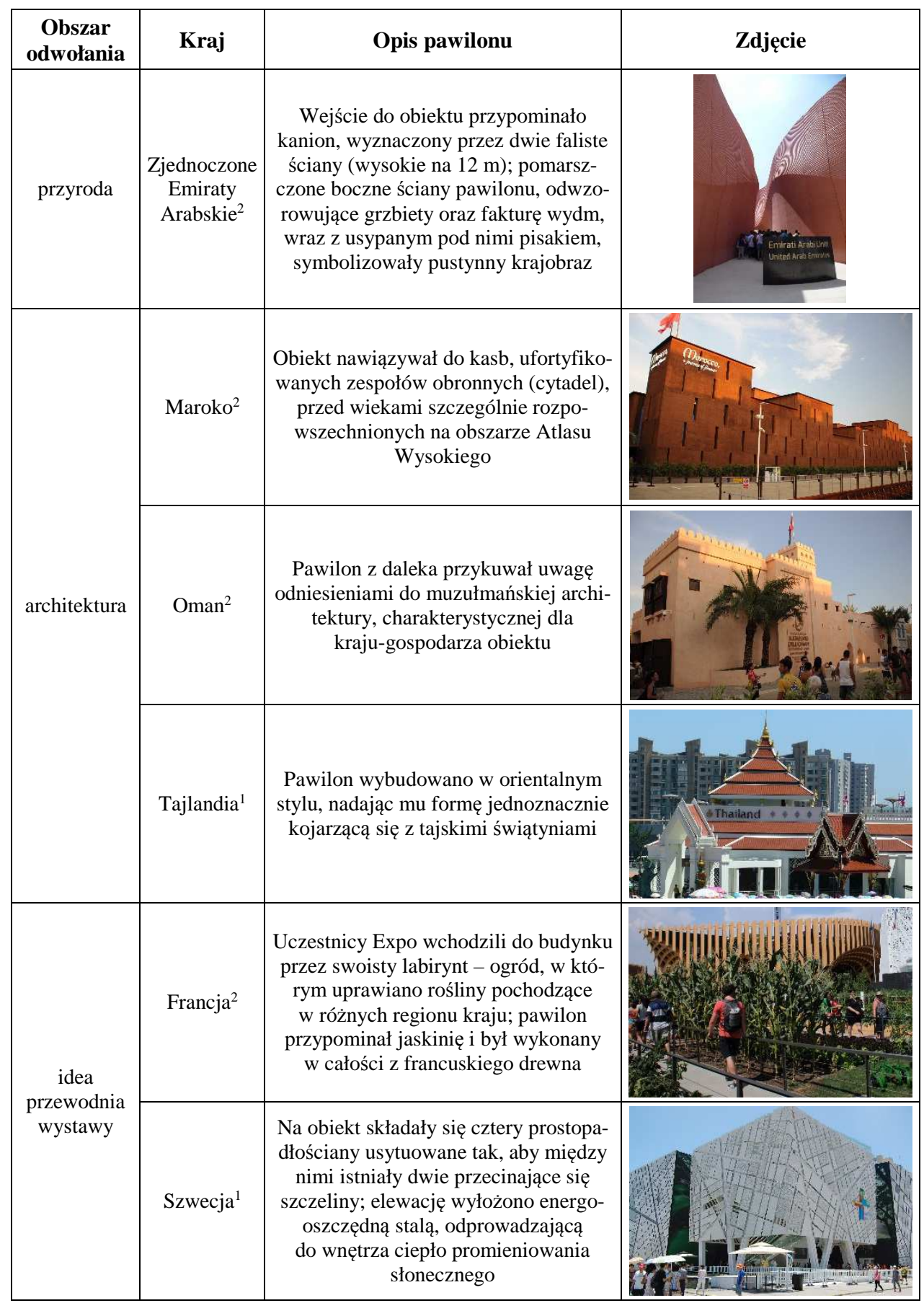


Tabela 2 (cd.). Przykłady pawilonów narodowych z różnych grup odwołań symbolicznych

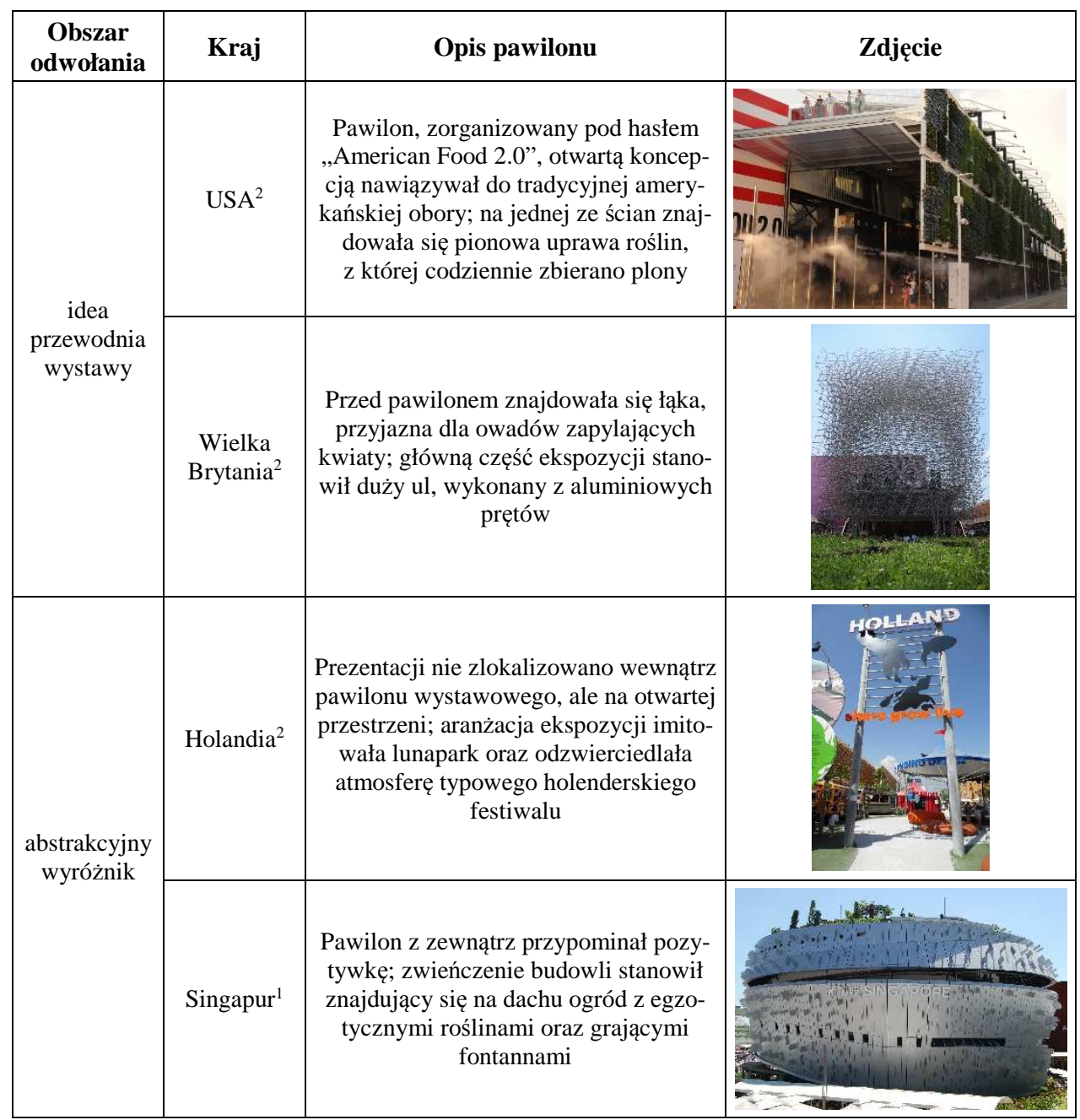

Legenda: ${ }^{1}$ - pawilony z Expo 2010, ${ }^{2}$ - pawilony z Expo 2015.

Źródło: opracowanie własne (w tym fotografie własne).

Jak już wcześniej wspomniano, polskie wystawiennictwo związane z Expo nie ma bogatej tradycji. Jednak we wszystkich przypadkach posiadania narodowych ekspozycji Polska prezentowała się w oryginalnych obiektach, cieszących się dużym zainteresowaniem uczestników wystaw. Podczas wydarzeń, które odbyły się w Szanghaju oraz Mediolanie, polskie pawilony wyróżniały się interesującą formą architektoniczną i nawiązywały do kultury lub tematu przewodniego Expo (tabela 3). 
Tabela 3. Architektura polskich pawilonów podczas wystaw światowych w 2010 i 2015 r.

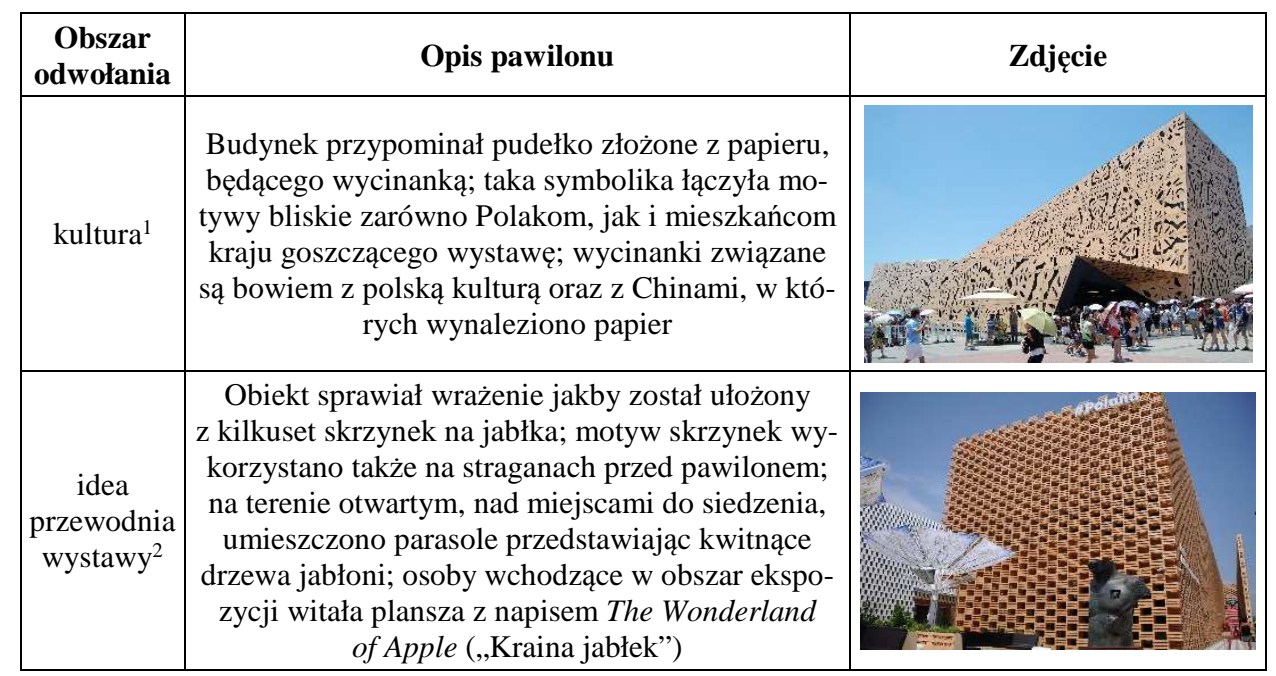

Legenda: ${ }^{1}$ - pawilon z Expo 2010, ${ }^{2}$ - pawilon z Expo 2015.

Źródło: opracowanie własne (w tym fotografie własne).

Każdej wystawie światowej - zarówno tej uniwersalnej, jak i specjalistycznej - przyświeca temat przewodni, odnoszący się do kwestii ważnych obecnie dla ludzkości. Podczas wystawy w Szanghaju było to motto „Lepsze miasto, lepsze życie” (Better City, Better Life), zaś w Mediolanie - „Wyżywienie planety. Energia dla życia” (Feeding the Planet, Energy for Life). Prezentacje państw uczestniczących w Expo powinny nawiązywać do wiodącej idei wydarzenia. Najczęściej, chociaż nie zawsze, takie odwołania silnie widać w przypadku ekspozycji wewnętrznych. Niektórym państwom udaje się jednak odwzorować główne motto w symbolice zewnętrznego wyglądu pawilonu (tak, jak m.in. Szwecji podczas Expo 2010), a niekiedy nawet wzbogacić bryłę pawilonu do dodatkowe elementy symboliczne - np. związane z gospodarką (jak miało to miejsce w przypadki Argentyny i Białorusi podczas Expo 2015) lub religią (przykładem jest pawilon Watykanu podczas mediolańskiej wystawy).

\section{PODSUMOWANIE}

Tereny wystaw światowych z pawilonami wznoszonymi jako obiekty tymczasowe, rozbierane po zakończeniu wydarzenia, stały się poligonem, na którym prezentowano najnowsze technologie, testowano nowe konstrukcje i formy, w sposób nieskrępowany poglądami tradycjonalistów, uwarunkowaniami kontekstu krajobrazowego czy obowiązujących przepisów, ograniczających swobodę twórczą ${ }^{17}$. Architektura obiektów, w których prezentowali

${ }^{17}$ I. Sykta, Wystawy międzynarodowe i ich wptyw na kształtowanie krajobrazu miast - próba retrospekcji i wspótczesnej oceny skutków krajobrazowych, „Teka Komisji Architektury, Urbanistyki i Studiów Krajobrazowych”, X/4 (2014), s. 5-6. 
się uczestnicy najważniejszych na świecie wystaw - ze względu na odwagę i swobodę twórczą, nowatorstwo, jak również zasięg oddziaływania - nabrała szczególnego znaczenia kulturowego i promocyjnego. To znaczenie sprawia, że omówienia pawilonów wystawowych powinny znaleźć należyte miejsce w publikacjach nie tylko z zakresu nauk technicznych, ale również nauk społecznych.

Do tej pory nie zaprezentowano w naukowej literaturze przedmiotu badań odnoszących się do tego, w jakim zakresie symbolika pawilonów narodowych wpływa na frekwencję odwiedzających ich uczestników Expo. Systematyka zaprezentowana w tym artykule może okazać się przydatna przy konstruowaniu narzędzia pomiarowego z myślą o przyszłych badaniach marketingowych realizowanych podczas Expo. Podczas ich realizacji należy jednak wziąć pod uwagę to, że nie tylko wygląd obiektu z prezentacja narodową decyduje o tym, ile osób, go odwiedzi, ale również: wielkość pawilonu, lokalizacja budowli (przy głównej alei lub na obrzeżach terenów wystawowych), wizerunek danego kraju (jego rozpoznawalność na arenie międzynarodowej oraz atrakcyjność dla zwiedzających, w tym przede wszystkim dla obywateli kraju-gospodarza Expo).

Ostatnie wystawy uniwersalne - te zorganizowane w XXI w. - pokazały, że zwiększa się rola abstrakcji w kształtowaniu obiektów. Staje się ona coraz wyraźniejsza w idei i inspiracjach. Pawilony wystawowe odrywają się od utrwalonego w powszechnym rozumieniu pojęcia „budynek”, coraz mniej go przypominając ${ }^{18}$. Pawilony stają się często już same w sobie symbolami - coraz częściej abstrakcyjnymi, wymagającymi odpowiedniego zdekodowania przez odbiorców, aby wywołać zamierzone przez wystawcę konotacje. Wykorzystywanie oryginalnych projektów, nowoczesnych materiałów budowalnych, zaawansowanych rozwiązań multimedialnych sprawia, że często powstają konstrukcje, których wygląd zewnętrzny staje się w wielu przypadkach charakterystycznym architektonicznym ,logiem" kraju, odgrywającym - w cyklu pięcioletnim - duże znaczenie w promocji globalnej.

\section{LITERATURA}

1. Bacchi U., Expo Milano 2015: Canada and Australia say no to world fair over budget, http://www.ibtimes.co.uk/expo-milano-2015-canada-australia-say-no-world-fair-overbudget-1499177.

2. Deng Y., Conceptualizing mega-event flagships - A case study of China Pavilion of Expo 2010 Shanghai China, „Frontiers of Architectural Research”, 2 (2013).

3. Dunaj B. (red.), Stownik wspótczesnego języka polskiego, Wilga, Warszawa 1996.

4. Harvey P., Nations on display: Technology and culture in Expo '92, „Science as Culture”, 5 (1992).

5. Hughes M., Making an impact: The power of World Expo, „Vision - Fresh Perspectives from Dubai”, March (2012).

6. Kopaliński W., Słownik wyrazów obcych i zwrotów obcojęzycznych z almanachem, Oficyna Wydawnicza Rytm, Warszawa 2007.

7. Świątek W., Trzy polskie pawilony na Wystawy Światowe Expo - trzy stopnie jakości, „Czasopismo Techniczne. Mechanika", 26 (2012).

\footnotetext{
${ }^{18}$ Por. W. Świątek, Trzy pawilony..., s. 347.
} 
8. Sykta I., Ewolucja idei postępu i wizji miast przyszłości zapisana w krajobrazach, obiektach i pokazach wystaw światowych - od Londynu 1851 do Nowego Jorku 1939, „Przestrzeń i Forma", 21 (2014).

9. Sykta I., Ewolucja idei postęu i wizji miast przyszłości zapisana w krajobrazach, obiektach i pokazach wystaw światowych - od Brukseli 1958 do Osaki 1970, „Przestrzeń i Forma”, 22 (2014).

10. Sykta I., Synergia terenów wystaw światowych i struktur przestrzennych miast-gospodarzy, „Budownictwo i Architektura”, 16(2) (2017).

11. Sykta I., Wystawy międzynarodowe i ich wptyw na ksztattowanie krajobrazu miast - próba retrospekcji i wspótczesnej oceny skutków krajobrazowych, „Teka Komisji Architektury, Urbanistyki i Studiów Krajobrazowych", X/4 (2014).

12. Wang J., The Shanghai Expo as a Site for Nation Branding [w:] Shaping China's Global Imagination: Branding Nations at the World Expo, Palgrave Macmillan, New York 2013.

13. Zhou Z., Chen Y., Scale study of sites and pavilions for World Expo 2010, „Frontiers of Architecture and Civil Engineering in China", 2(1) (2008).

\title{
SYMBOLISM OF NATIONAL PAVILIONS AT WORLD EXPOSITIONS
}

\begin{abstract}
World expositions continue an almost 150-year tradition. Their functions had changed over time - originally, they were organised to exhibit technical accomplishments and inventions, subsequently, cultural achievements were promoted. Nowadays, the main role of universal expositions is to enable participating countries to create their image. In that regard, the key importance is attached to the symbolism of national pavilions, as it is the original appearance of these structures that encourages Expo visitors to see a given exhibition, becomes embedded in their memories for long and is often presented in media coverage. This paper aims to systematize individual national pavilions erected for the last two world exhibitions - Expo 2010 in Shanghai and Expo 2015 in Milan. Based on the author's observation, a classification of national pavilions has been put forward in the context of their symbolic dimension by providing numerous examples. The main findings that emerged from the observation imply that the symbolic nature of Expo structures is limited to references to the following attributes of countries participating in Expo: culture, history, religion, economy, nature, architecture. The symbolism of structures with national exhibitions may also refer directly to the central idea of an exposition, as well as to other (abstract) elements. Assigning the symbolic dimension of pavilions to categories defined may be useful in developing a measuring instrument to be used in research into the perception of national exhibitions, which will be conducted during future Expo editions. The article also describes briefly the development of world expos and the diversification of structures which are built at territory of contemporary Expos.
\end{abstract}

Keywords: world expositions, Expo, symbolism of buildings, national pavilions.

DOI: $10.7862 /$ rz.2018.hss.38

Przestano do redakcji: marzec $2018 \mathrm{r}$.

Przyjęto do druku: wrzesień 2018 r. 
